\title{
Ultrastructural Findings in Acrodermatitis Enteropathica
}

\author{
Ingrid Lombeck, ${ }^{[20]}$ D. B. von Bassewitz, K. Becker, \\ P. Tinschmann and Hertha Kästner \\ University Childrens Hospital, Departments of Metabolic and Renal Diseases and Gastroenterology, Düsseldorf, and \\ University of Münster, Departments of Medical Ultrastructure Research and Dermatology, \\ Münster, West Germany
}

\begin{abstract}
Extract
Duodenal biopsies from patients with acrodermatitis enteropathica were examined by electron microscopy and dissecting microscopy. The ultrastructural studies revealed characteristic inclusions in Paneth cells with a maximum length of $7 \mu \mathrm{m}$. These findings were constant in four different patients. A follow-up study in one patient showed the same alterations before and after treatment.
\end{abstract}

\section{Speculation}

The biochemical defect of acrodermatitis enteropathica is unknown and, therefore, typical ultrastructural alterations challenge one to investigate the nature of the included material.

\section{Introduction}

Acrodermatitis enteropathica is a hereditary disease of unknown etiology with epidermal lesions, gastrointestinal symptoms, alopecia, and psychic disturbance first described in 1936 [2] and 1942 [4].

Many theories regarding the etiology of this disease have been offered, for example, infections with monilia [1] and parasites [9], decreased activity of mucosal enzymes which result in an absorption of a hypothetic toxic polypeptide $[10,11]$, or a defect in tryptophan metabolism [8].

In 1969 it was suggested that the interconversion of linoleic to arachidonic acid is disturbed [3]. This paper concerns previously undescribed ultrastructural changes of the duodenal mucosa.

\section{Case Report}

Case I. ER, born in 1970, the 4th boy of healthy unrelated parents, suffered from diarrhea and skin eruptions around the body orifices from early infancy. After several remissions, the skin lesions got worse. A severe malnutrition and a total alopecia of the scalp, eyebrows, and eyelashes followed.

At admission in our hospital his weight $(6.7 \mathrm{~kg})$ and his height $(78 \mathrm{~cm})$ lay far below the 3rd percentile for his age of 13 months. The skin lesions, crops of bullae, crusts, and denuded patches involved the face, neck, buttocks, and extremities, especially the fingers and toes. Besides total alopecia there were conjunctivitis, stomatitis, and paronychia. Proctosigmoidoscopy showed pale mucosa with a reduced vascular structure.

Treatment with fresh human milk and diiodohydroxyquin [16], $750 \mathrm{mg} / 24 \mathrm{hr}$, was successful. The skin lesions healed, the hair grew, the diarrhea stopped, and the surface of the rectal mucosa looked normal. 
When the child had gained $5 \mathrm{~kg}$ after 7 months of treatment, human milk was replaced by normal food, while drug therapy was continued. Duodenal biopsies were performed before, 6 weeks, 7 months, and 12 months after starting treatment.
Case $I I . H R$, born in 1969, single boy of healthy consanguineous parents, suffered from diarrhea and typical skin lesions from the 2nd week of life. Several remissions and relapses were followed by total alopecia. Because of severe intestinal symptoms in the 3rd

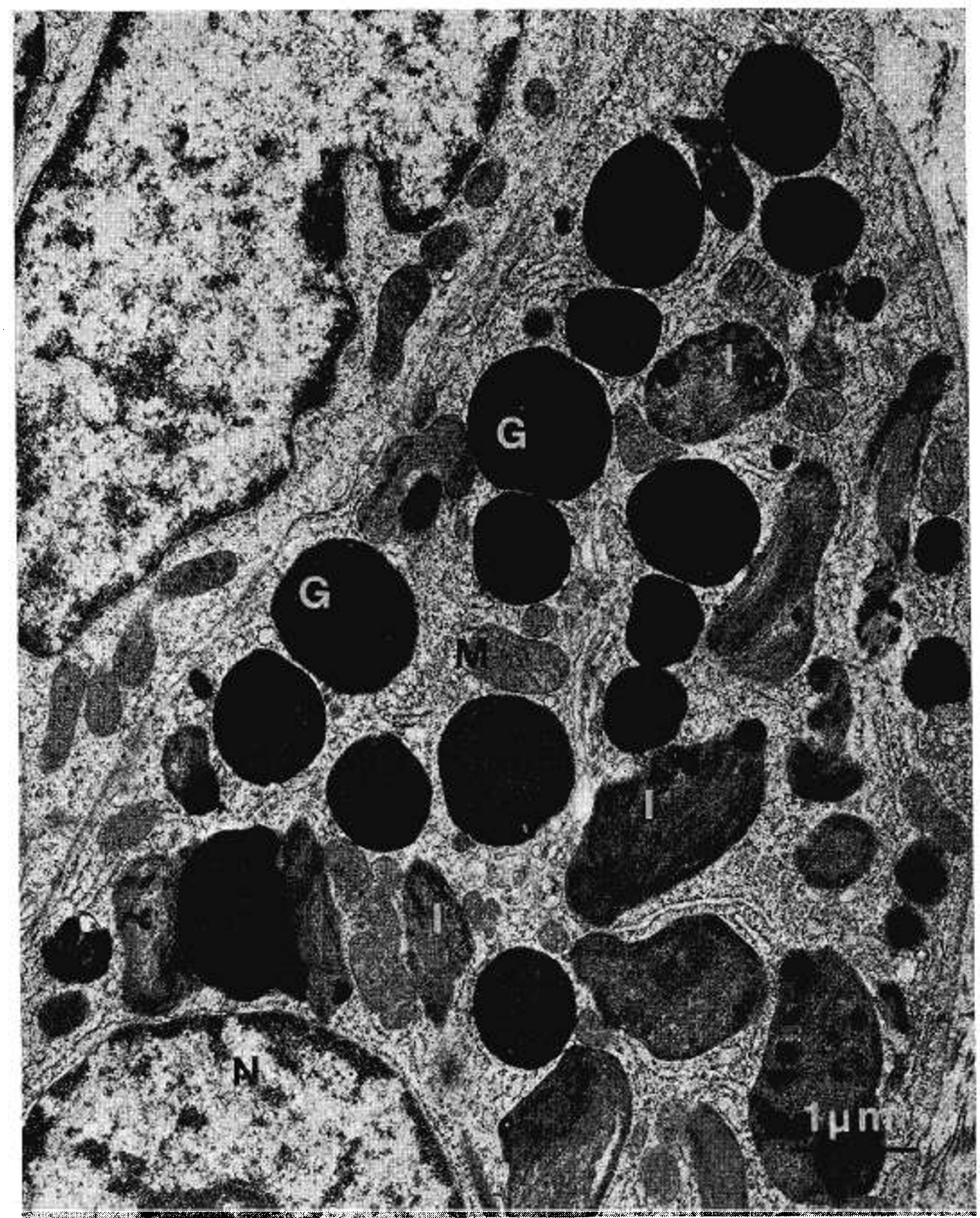

Fig. 1. Paneth cell from duodenal biopsy. Nucleus $(N)$, mitochondrium $(M)$, granula $(G)$, and inclusions $(I)$ of different electron density. $\times \quad 18,000$. 
year, treatment with human milk and diiodohydroxyquin was started. The boy recovered. Three months later a duodenal biopsy was performed.

Case III. EP, born in 1954, single girl of healthy unrelated parents, suffered from dermatitis, alopecia, and diarrhea after breast feeding was replaced by cow's milk formula in the 6 th month of life. In correspondence with the clinical course, intermittent therapy with diiodohydroxiquine was performed. A duodenal biopsy was obtained in 1969 .

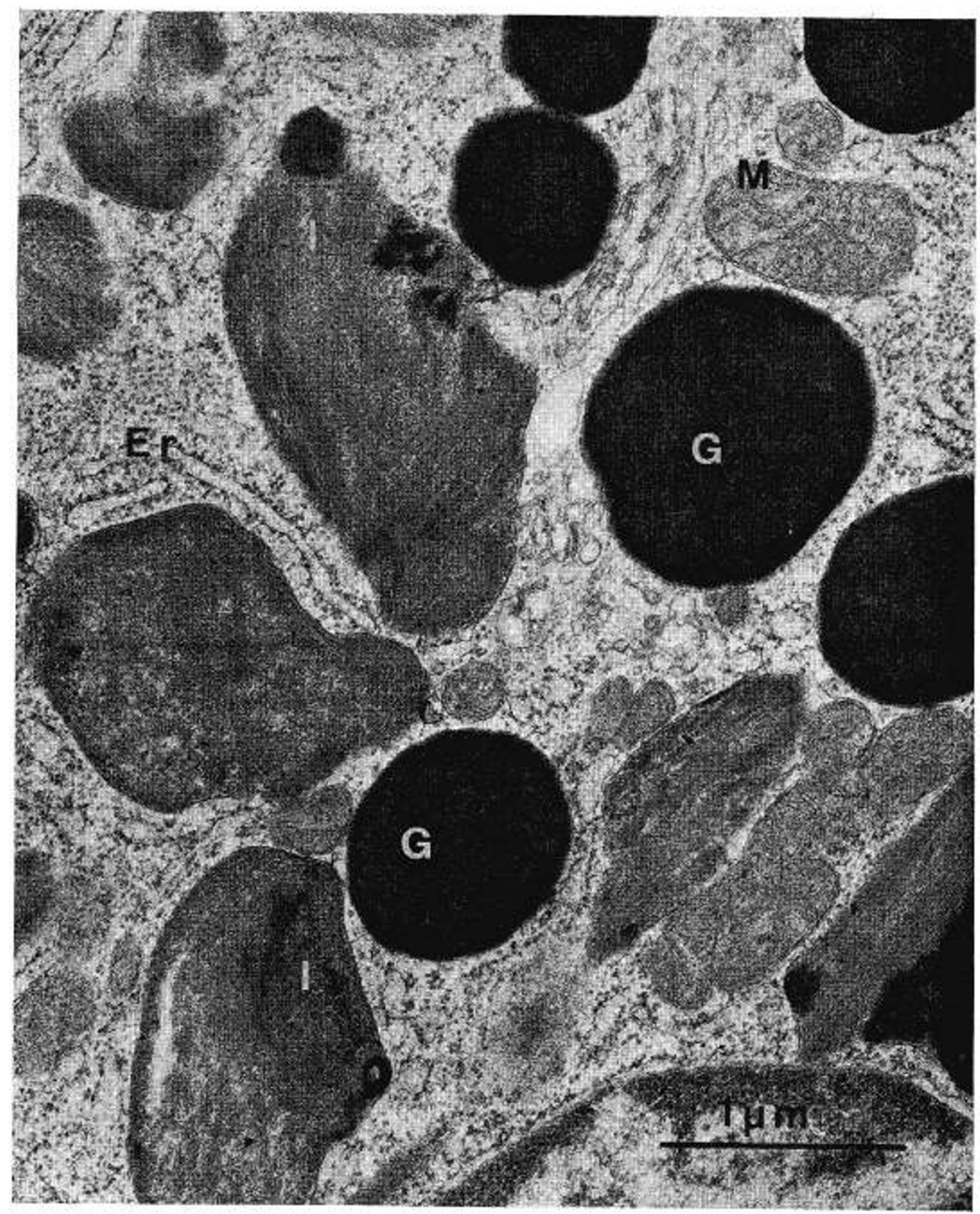

Fig. 2. Inclusion bodies $(I)$ in Paneth cell with filamentous substructure. Granula $(G)$, mitochondrium $(M)$, and rough endoplasmic reticu$\operatorname{lum}\left(E_{r}\right) . \times 36,500$. 
Case IV. RM, born in 1950 , showed the typical features of acrodermatitis enteropathica since infancy; the diagnosis was performed in 1959, and despite the medicamental therapy relapses occurred frequently. Jejunal biopsy was performed in 1972.

\section{Materials and Methods}

The biopsy specimens were obtained for the duodenaljejunal junction by Crosby capsule [12]. The mucosal specimens, which measured about $5 \times 8 \mathrm{~mm}$, were divided immediately into two parts: one was fixed in $4 \%$ neutral formol and examined under dissecting microscope, the other part was fixed in $2.25 \%$ glutaraldehyde, pH 7.4, with $0.05 \mathrm{~m}$ phosphate buffer at $4^{\circ}$ for 2 hr. After overnight washing in 0.05 phosphate buffer, $\mathrm{pH} 7.4$, the tissues were postfixed in $1.33 \%$ osmium tetroxide, pH 7.4. After dehydration in graded ethanol, the specimens were embedded in Epon 812, sections were cut on a microtome [17], stained with uranyl acetate and lead citrate, and examined using electron microscopy [18].

\section{Results}

\section{Dissecting Microscopy}

Ca'se $I$. The first biopsy obtained before treatment presented a pathologic mucosal architecture; the surface showed broadened, flat ridges lacking any normal villi, forming uniform parallel folds. Six weeks later under treatment the ridges became higher, and after another 6 months the regeneration was almost complete. The biopsy performed after 1 year of therapy showed normal mucosal architecture.

Cases II-IV. Duodenal and jejunal biopsies obtained at the age of 2.5 years, 14.5 years, and 21.5 years showed normal mucosa.

\section{Electron Microscopy}

Cases $I-I V$. The Paneth cells showed lysosome-like structures, which were located predominantly in the basal part of the cell (Fig. 1). These cells were not increased in number. Organelles like mitochondria, rough endoplasmic reticulum, Golgi complexes, and

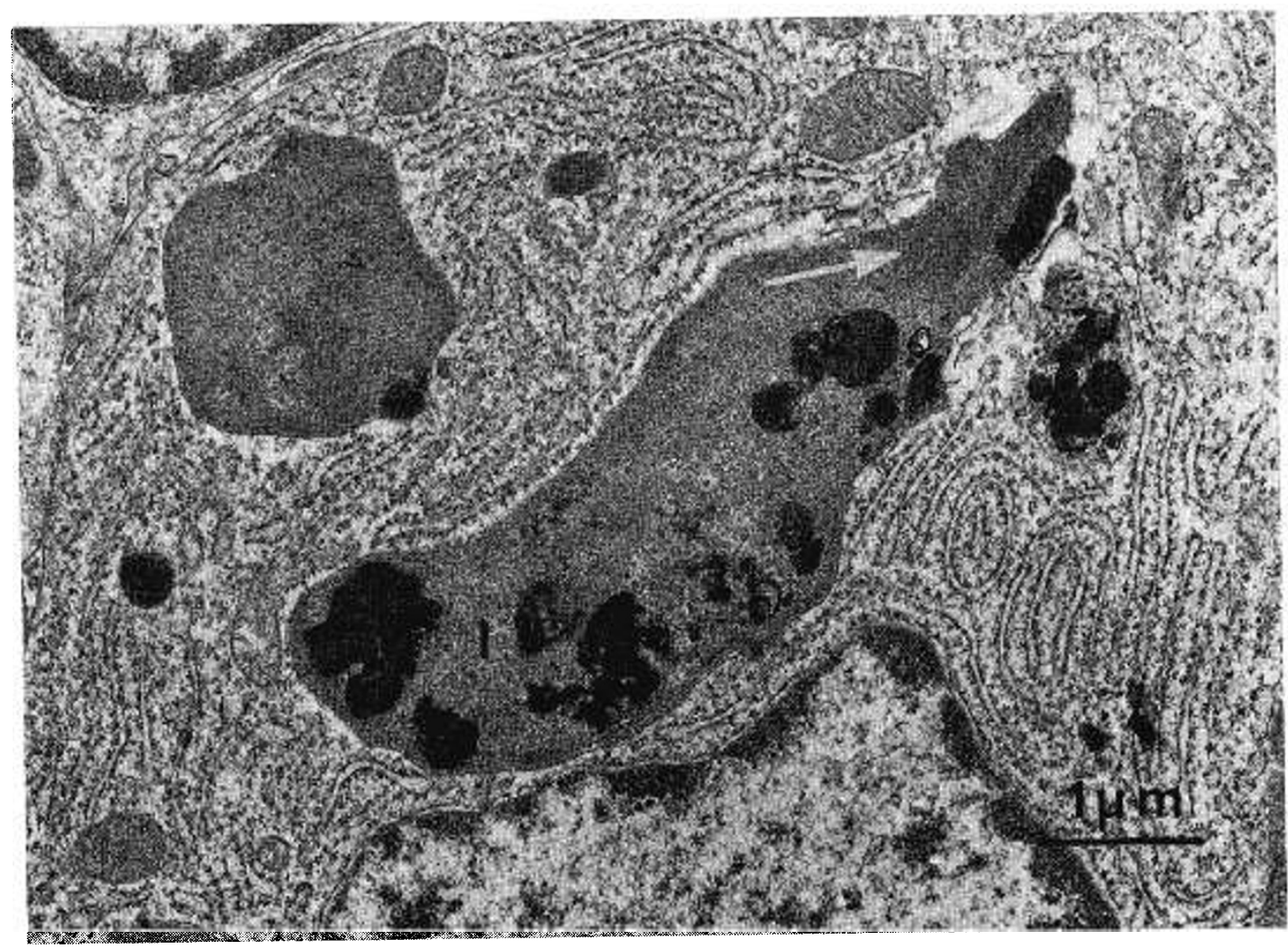

Fig. 3. Patient $I$. Inclusion bodies $(I)$ containing electron dense myelin-like material and paracrystalline arrays $($ arrow). $\times 18,500$. 

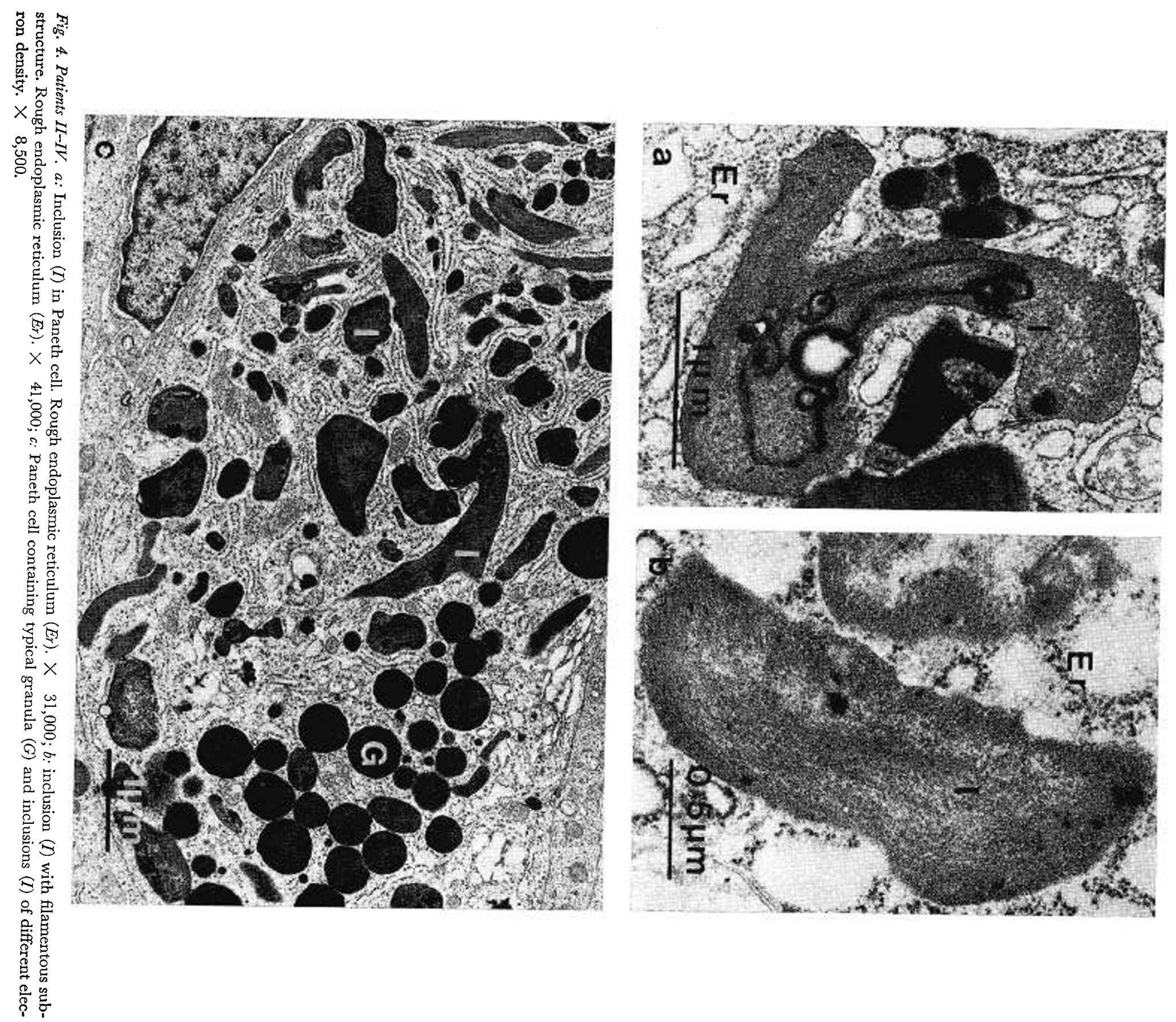
typical granula of these pyramidally shaped cells were well developed. The atypical structures had an ovoid or often rhomboid figure with a maximal length of 7 $\mu \mathrm{m}$, and exhibited a characteristic ultrastructure; an electron-dense, myelin-like material was embedded in a filamentous matrix (Figs. 2 and 3). The matrix filaments were often arranged in a paracrystalline pattern (Fig. 3).

The atypical structures in the Paneth cells were observed in all seven biopsies of four different patients (Fig. 4), whereas the findings in other mucosa cells varied.

Before therapy of patient I the mucosa was flat, the epithelial brush border irregularly shaped. Some epithelial cells were characterized by a loss of microvilli. The terminal web of almost all epithelial cells was undeveloped. Cell organelles and cytoplasm of enterocytes were of normal appearance, except that an increase in lysosomes was noted. The mucosal goblet cells appeared to be normal. The intraepithelial lymphocytes were not increased in number, while the lamina propria of the specimens was heavily infiltrated by plasma cells, granulocytes, lymphocytes, and eosinophilic leucocytes. Macrophages and mast cells could be observed also. After starting medical treatment, the changes in the enterocytes were less pronounced. Villous formation was evident.

In patients $I I, I I I$, and $I V$, the mucosa cells were normal. No ultrastructural changes could be demonstrated except the findings described in Paneth cells.

\section{Discussion}

The clinical data in our four cases are in agreement with the typical features of acrodermatitis enteropathica. Former ultrastructural studies [10, 11] failed to reveal a constant abnormality and follow-up biopsy series were not done. The authors reported that the structure of the mucosa was unaltered but that the enzymatic functions were impaired [10, 11, 13]. In only one case they found a mild vacuolization of enterocytic cytoplasm and a dilatation of extracellular space.

In our cases the findings in enterocytes correspond to those cited above except the temporary loss of microvilli in case $I$. However, Paneth cells in seven biopsies showed characteristic lysosome-like structures not mentioned before and not seen in our own laboratory in other diseases. Careful studies of 26 other jejunal biopsies obtained from 2 subjects with celiac disease, 4 subjects with nontropical sprue, 10 subjects with psoriasis, and 10 subjects without intestinal diseases did not reveal any similar finding in Paneth cells [15].
The nature of the stored material in acrodermatitis enteropathica is unknown. It is impossible at this moment to reveal any link between this morphologic abnormality and impaired fatty metabolism [3], tryptophan metabolism [5, 8], or increased phagocytic activity of Paneth cells $[6,7]$. It is striking that these changes remain unaltered during the whole clinical course and during medical treatment, and can be demonstrated at various ages. These findings support the hypothesis that the inclusions are not secondary phenomena but a morphologic manifestation of the primary defect in acrodermatitis enteropathica.

\section{Summary}

Duodenal and jejunal biopsies were performed in four patients with acrodermatitis enteropathica. Electron microscopy showed atypical lysosome-like structures in Paneth cells.

\section{References and Notes}

1. BAIRD, K. H.: Unusual syndrome associated with Candida albicans infection. Pediatrics, 4: 730 (1949).

2. BRANDT, T.: Dermatitis in children with disturbances of the general condition and the absorption of food elements. Acta Dermato-Venereol., 17:513 (1936).

3. CASH, R., AND BeRger, C. K.: Acrodermatitis enteropathica. Defective metabolism of unsaturated fatty acids. J. Pediat., 74: 717 (1969).

4. Danbolt, N., and Closs, K.: Acrodermatitis enteropathica. Acta Dermato-Venereol., 23: 127 (1942).

5. Dillaha, C. J., Lorincz, A. L., AND Aavic, O. R.: Acrodermatitis enteropathica, review of the literature and report of a case successfully treated with Diodoquin. J. Amer. Med. Ass., 152: 509 (1953).

6. Erlandsen, S. L., and Chase, D. G.: Paneth cell function: Phagocystosis and intracellular digestion of intestinal microorganism. I. Hexamita muris. J. Ultrastr. Res., 41: 296 (1972).

7. Erlandsen, S. L., and Chase, D. G.: Paneth cell function: Phagocytosis and intracellular digestion of microorganism. II. Spiral microorganism. J. Ultrastr. Res., 41: 319 (1972).

8. Hansson, O.: Acrodermatitis enteropathica: Report of two cases with a hypothesis concerning the pathogenesis of the disease. Acta Dermato-Venereol., 43: 456 (1963).

9. Ilic, S., AND Lalevic, B.: Contribution to the problem of acrodermatitis enteropathica. Dermatologica, 117: 317 (1958).

10. Moynahan, E. J.: Acrodermatitis enteropathica. Proc. Roy. Soc. Med., 55: 240 (1962).

11. Moynahan, E. J., Johnson, F. R., ANd McMinn, R. M.: Acrodermatitis enteropathica: Demonstration of possible intestinal enzyme defect. Proc. Roy. Soc. Med., 56: 300 (1963).

12. McCarthy, C. F., Gough, K. R., Rodriguez, M., and Read, A. E.: Peroral intestinal mucosal biopsy with small Crosby capsule. Brit. Med. J., I: 162 (1964).

13. Mrlla, P. J.: Acrodermatitis enteropathica with lactosein tolerance. Proc. Roy. Soc. Med., 65: 600 (1972).

14. OTto, H. F., AND FeTr, R.: Zur Orthologie und Pathologie 
Panethscher Körnerzellen. Virchows Arch. Abt., A Pathol. Anat., 356: 187 (1972).

15. von Bassewitz, D. B., and Themann, H.: Unpublished data.

16. Entero-Vioform, Ciba-Geigy, AG, Basel, Switzerland.

17. MT 1, Porter-Blum, Ivan Sorvall, Inc., Norwalk, Conn.

18. EM 300, Philips Electronic Instruments, N. V. Philips, Sloeilampen-Fabrieken, Eindhoven, The Netherlands.

19. This research was supported by Landesamt für Forschung,
Ministerium für Wissenschaft und Forschung, NordrheinWestfalen, Düsseldorf, West Germany.

20. Requests for reprints should be addressed to: INGRID LoMBECK, University Children's Hospital, Department of Metabolic and Renal Diseases, D-4 Düsseldorf, Moorenstrasse 5, West Germany.

21. Accepted for publication September 26, 1973. 